\title{
Position in the World-System and National Emissions of Greenhouse Gases*
}

\author{
by
}

\section{Thomas J. Burns}

Department of Sociology

University of Utah

Salt Lake City, Utah 84112

Burns@soc.utah.edu

\author{
Byron L. Davis \\ Department of Sociology \\ University of Utah
}

\author{
Edward L. Kick \\ Department of Sociology \\ University of Utah
}

Cite: Burns, Thomas J., Byron L. Davis, and Edward L. Kick. (1997). "Position in the World-System and National Emissions of Greenhouse Gases." Journal of World-Systems Research 3: 432 - 466.

*An earlier version of this paper was presented at the National Third World Studies Conference, Omaha, Nebraska, October 1995.

C 1997 Thomas J. Burns, Byron L. Davis, and Edward L. Kick.

[Page 432]

Journal of World-Systems Research

\section{INTRODUCTION}

The "greenhouse effect" is the Earth's trapping of infrared radiation or heat. Physical scientists have linked the greenhouse effect to the emission of two primary sources, or "greenhouse gases" - carbon dioxide and methane. While this in itself is a naturallyoccurring phenomenon, the amount of trapped heat has increased substantially along with heightened human production and consumption. In fact, the amount of heat trapped in the earth's atmosphere through the greenhouse effect has risen dramatically in the last thirty years, and has done so in rough proportion to the loss of world carbon sinks (most notably through deforestation) in that same period (Grimes and Roberts 1995; Schneider 1989).

Despite the apparent importance of these dynamics, there is relatively little social science theorization and cross-national research on such global environmental issues. There is 
especially a paucity of cross-national, quantitative research in sociology that focuses on the social antecedents to environmental outcomes (for exceptions, see Burns et al. 1994, 1995; Kick et al. 1996; Grimes and Roberts 1995). We find this condition surprising given the substantial initial work of environmental sociologists (Dunlap and Catton 1978, 1979; Buttel 1987) and the key role social scientists might in principle play in addressing such worldwide problems (Laska 1993). As a consequence, we propose and assess a perspective on the global and national social causes of one environmental dynamic, the greenhouse effect.

[Page 433]

Journal of World-Systems Research

\section{THE NATURE OF GREENHOUSE GASES}

For present purposes it is sufficient to underscore just a few essentials about the "greenhouse effect." It refers to the atmospheric trapping of heat that, for the most part, emanates from natural compounds (e.g., carbon dioxide, methane), but it is vitally important to recognize that global social life has greatly augmented the concentration of these and other gases. Physical scientists theorize that if this human-generated trend continues, global climatic changes will occur that have serious, if not catastrophic, longterm effects (e.g. Schneider 1989; CDAC 1983). These effects range from the destruction of agriculture to mammoth flooding as a result of the melting of the polar ice caps.

The most important human-produced greenhouse gas is carbon dioxide (CO2), which is primarily a product of fossil fuel usage. The United States is the largest global emitter of $\mathrm{CO} 2$, followed by the former U.S.S.R., China, India, and Germany. Net amounts of $\mathrm{CO} 2$ are also increased through human land use, especially as it involves deforestation. Because forests are the primary locus of $\mathrm{CO} 2$-oxygen exchange, their depletion reduces the rate of natural $\mathrm{CO} 2$ uptake.

Large amounts of another greenhouse gas, methane (CH4), similarly result from wet rice agriculture, livestock, uncontrolled coal mine emissions, and petroleum and natural gas leakages (World Resources Institute 1994:199-202, 361-272). China is the world's leading emitter of methane, followed by India, the United States, Brazil, and Bulgaria.

[Page 434]

Journal of World-Systems Research

It should be emphasized that the social dynamics leading to $\mathrm{CO} 2, \mathrm{CH} 4$ and to environmental degradation generally, may operate quite differently across structural positions in the world-system (Olsen 1990; Burns et al. 1994, 1995; Kick et al. 1996; Grimes and Roberts 1993), and that these dynamics themselves depend upon global 
processes (e.g. Kone 1993; Thiele and Wiebelt 1993; Bunker 1984). It is to these latter theoretical linkages that we now turn.

\section{THEORETICAL FRAMEWORK: THE WORLD-SYSTEM, NATIONAL DEVELOPMENT, POPULATION, AND GREENHOUSE GASES}

World-system theorists provide a framework focusing on global processes and their influences on national outcomes. Wallerstein (1974:390 ff.), for instance, identifies a world economy that for centuries has promulgated power and dependency linkages among nations of the world. He argues that global power-dependency relationships are reflected in an international division of labor that encompasses core, semiperipheral and peripheral countries. Core nations, including the major powers of Western Europe, the United States, Canada, and Japan dominate global production by virtue of their domestic and international strength. For Wallerstein, this strength is primarily economic in nature (for models acknowledging other dimensions of international strength, see Snyder and Kick 1979; Kick et al. 1995; Terlouw 1993).

In the short run at least, core countries thereby ensure their wealth, economic expansion and technological advancement. When coupled with relatively low population growth, these serve to maintain a high standard of living for core nations, reflected in their role as the primary consumer of the world's resources, including its energy reserves (see Rosa et al. 1988; also see Cook 1971).

[Page 435]

Journal of World-Systems Research

According to conventional world-system arguments, the countries in the periphery of the world-system-the least-developed nations in Africa and Asia (e.g., Bangladesh, Rwanda) - are relatively weaker than the core and, to a lesser extent, the semiperiphery (e.g., Chile, Libya). As a result they remain underdeveloped, and experience the domestic conditions that accompany a relatively low standard of living. As an illustration, consider that the commodity exports of peripheral countries often are highly concentrated, even more so than the semiperiphery's; as such, these countries are comparably vulnerable on international exchange networks (Kone 1993; Thiele and Wi ebelt 1993).

These dynamics, when coupled with initial disadvantage due at least in part to international geography, as well as to political-military, cultural and technical dependency, have severely limited national wealth and the economic growth potential of the periphery. These disadvantages limit technical progress and in turn foster virtually unchecked population growth, which ensure the substantially rural and agrarian character of the periphery's labor force (Elnagheeb and Bromley 1994).

Semiperipheral countries have characteristics of both the core and the periphery (Terlouw 1993; Arrighi and Drangel 1986:12). Further, they mediate between the core and the 
periphery in the world-system. The economically and politically stronger nation-states of Africa, Latin America and Asia, for example, exercise a not insignificant degree of control over exchanges with the periphery, despite their own economic political-military, cultural and technological dependence upon the core. Relatedly, semiperipheral countrie s occupy an intermediate position in terms of their per capita product, and are technologically, economically, and militarily advantaged relative to the periphery. Not unlike the periphery, the semiperiphery is undergoing rapid population growth, but unlike the periphery, semiperipheral populations typically are more highly urbanized as they undergo rapid social change.

[Page 436]

Journal of World-Systems Research

Although the short-term a priori odds of any given nation experiencing world-system mobility are slim, many countries in the semiperiphery have a strong motive and related potential for upward mobility in the system (Chase-Dunn 1990; Wallerstein 1979; Arrighi and Drangel 1986). A country maximizes its chances of mobility by utilizing what advantages it does have relative to others. For example, a semiperipheral country is likely to emphasize its revenue-generating capability relative to the periphery, but its cost-advantage relative to the core (Arrighi and Drangel 1986:27). Partly as a result of this process, some of the countries in the semiperiphery have become more industrialized than some of those in the core (Arrighi and Drangel 1986).

[Page 437]

Joumal of World-Systems Research

Stern et al. (1992) point out that demands for energy have peaked in some core countries. This can be attributed, in part, to the movement of heavy industry out of the core and to the semiperiphery. Thus, a high standard of living, mass consumption, and mammoth energy usage still characterize the core (Arrighi and Drangel 1992), while industrialization increasingly typifies the semiperiphery.

The semiperipheral countries most likely to acquire and maintain heavy industry are those with the strongest network ties to other countries who could potentially serve as markets for the goods produced-most notably the mass consumption societies of the core. A similar logic applies to agricultural production and export-a disproportionate share of agricultural production which is connected to international markets, occurs in the stronger (by which we primarily mean more tightly networked) nations of the semiperiphery.

While the long-term outcome may not be successful, semiperipheral nations attempt to use their relative advantages in hopes of attaining world-system mobility. But as Terlouw 
(1993) contends: "a semiperipheral state who wants to improve its position in the worldsystem must first of all strengthen its state apparatus" (p.96).

[Page 438]

Journal of World-Systems Research

A strong semiperipheral state apparatus depends in the modern world economy on heightened industrial or agricultural production which, regrettably, frequently bypasses the health and environmental safeguards that commonly attend such production in core countries. Further, it was those countries that were core-like in some respects (e.g. political), but not in others (e.g. economic), which were most likely to undergo crises. During such crises, environmental concerns are most likely to take a back seat to more immediate ones. Crises thus are likely to contain the potential for ecological catastrophe, and the loci of many such crises are likely to be in the semiperiphery 1 .

In making such arguments, we acknowledge that despite its theoretical utility, the semiperiphery as a theoretical and empirical construct is the least well-defined of the three major sectors of the world-system. Depending upon the definition used, as much as two-thirds of the world's population resides in a semiperipheral country. As Terlouw (1993) points out: "The vast majority of states have been classified at least once as semiperipheral, but no state is always allocated to the semiperiphery...[t]he diversity of states which are thus classified as semiperipheral is striking" (pp. 88-89).

Distinctions can be drawn within the "semiperiphery" category. While by definition, semiperipheral states are stronger economically, politically or militarily than peripheral states, the omnibus "semiperiphery" categorization masks important differences in the transnational power and dependency linkages of lesser-developed countries in Western and Eastern Europe (e.g., Finland, Bulgaria), relative to third-world countries (e.g., Egypt, Columbia).

[Page 439]

Journal of World-Systems Research

A number of theorists have pointed to distinctions within the semiperiphery, based on either internal characteristics (e.g. Arrighi and Drangel 1986), or international characteristics (e.g. Nemeth and Smith 1985; Smith and White 1992; Snyder and Kick 1979; Kick 1987).

In this paper, we distinguish between stronger states and weaker states in the semiperiphery. This strength can be seen primarily in terms of global network ties, but typically is reflected domestically as well. In line with earlier work (Snyder and Kick 1979; Kick 1987), we adopt a categorization in which we label the stronger parts of the semiperiphery as "semicore," and for the weaker states (in the semiperiphery) we maintain the term "semiperiphery" (see Appendix I). In so doing, we acknowledge salient 
differences between the periphery and semiperiphery in global power and dependency networks, as well as corresponding variations in their respective standards of living.

Terlouw (1993) posits two primary aspects of power in the semiperiphery (economic and political). In what Terlouw terms the "ideal typical semiperiphery" (p. 92), the economic and political dimensions correspond closely to one another. It is these cases typically that fall into what we term the "semiperiphery" in this paper. However, there are a number of cases in which the political strength and economic strength of a country do not match. In cases in which one aspect (e.g. the economy) is largely semiperipheral in character, but the other (e.g. the polity) is significantly stronger than would otherwise be the case in a semiperipheral country, we classify as the "semicore". Since it is not truly part of the core, because of a relatively weak position in either the economy or the polity, we do not combine the semicore with the core. Rather, we treat it as an analytically distinct part of the world-system.

[Page 440]

Journal of World-Systems Research

Some elaboration on characteristics of the "semicore" (e.g., Brazil, Norway) category is, of course, required. Semicore nations occupy an intermediate position in the worldsystem between the core and the periphery. Unlike the weaker semiperiphery, however, the semicore has some characteristic that approaches the core, such as in the politicalmilitary, economic, cultural or technological realm. This position is supported by the semicore's national characteristics and their position of power over the semiperiphery and periphery. The semicore cannot compete with the core uniformly, however.

As a result of their world-system position, semicore countries rank between the core and the weaker semiperiphery (which in turn ranks ahead of the periphery) in their levels of per capita product. The semicore has been rapidly industrializing, under conditions of relatively level population growth and technological advancement. Further, the semicore is urbanizing as its population becomes more highly educated than populations in the weaker semiperiphery and periphery (c.f. London 1987). In a related vein, the labor forces of semicore nations are increasingly employed in the manufacturing and service occupations that attend rapid industrialization.

These overall characteristics of core, semicore, semiperipheral and peripheral nations influence the magnitude and nature of environmental degradation that they are likely to experience. Because of the institutional and technological differences among countries comprising the respective sectors, the proximate causes of such degradation are likely to differ by sector as well (for an expansion of this theme in terms of social causes of deforestation, see Burns et al. 1994).

[Page 441]

Joumal of World-Systems Research 
Because of their respective positions in the world-system, core countries are the wealthiest economies in the world; this permits ever greater expansion of their economic institutions, technology, and industry. Such technological prowess permits the core to set production and consumption strategies that aggravate (or, at least potentially, alleviate) production of industrial $\mathrm{CO} 2$. Also, when coupled with their abundant natural resources, core countries' technological and economic advantages afford them a far greater physical ability to degrade the environment - a fact reflected in, inter alia, greenhouse gas emissions. Additionally, the indirect effects of core power on greenhouse gas emissions as by, for example, other environmental degradation such as deforestation, can hardly be overemphasized. The core has a far greater ability, because of its technological and infrastructural advantages, to deforest (and to reforest) than the non-core (Burns et al. 1994; Kick et al. 1996), and thereby to magnify or limit CO2 emissions resulting from land-use decisions.

Peripheral countries continue to experience low wealth levels and relative economic constriction. Relative to the core, they sustain enormous population growth - growth which often results in further intrusion into hinterland areas (Kaoneka and Solberg 1994), with population pressures that spur other types of environmental degradation (Anderson 1990; Niang 1990), including the very land-use changes that generate CO2 and methane concentrations.

[Page 442]

Journal of World-Systems Research

Even the weaker semiperipheral nations have profiles that differ significantly from the periphery. This is largely a function of international networks of which they are a part, but is reflected in their internal characteristics as well. While such weak semiperipheral countries would have a difficult time competing with the stronger semicore countries, they are in an advantaged position relative to truly peripheral countries. Semiperipheral Guatemala, for example, has a per capita GNP that is four times higher than the peripheral country, Zambia. This is largely attributable to the fact that even the poorer countries of Central America are more integrated into world networks than are truly peripheral countries.

The semiperiphery, due ultimately to its world networks position, has its own characteristic and proximal causes of environmental degradation. While increases in population, especially in urban areas, precipitate encroachment into forested regions (Burns et al. 1994; Miller et al. 1991), and their eventual development into industrial usage, more typically this encroachment results in land being used for agriculture. In semiperipheral countries especially, this agriculture is commonly geared to cattle and other kinds of livestock production for export to core countries (DeWalt 1983).

If the semiperiphery has unique characteristics that are reflected in its impact on the environment, so too does the semicore. It is precisely in the semicore that the least 
isomorphism between economic and political strength has occurred, at least in recent years. Many, if not most, of the semicore countries have had major upheavals in the last decade. This relative lack of isomorphism between political and economic power would, ceteris paribus, imply some relatively major advantage and disadvantage disparities between themselves and other countries - the core on one side, and the weaker semiperiphery on the other.

[Page 443]

Journal of World-Systems Research

The industrialized countries of the semicore are potentially upwardly mobile in the world system (c.f. Chase-Dunn 1990; So 1990; Wallerstein 1979). As a result, they are in many respects undergoing more rapid change than either periphery or core nations and, to an extent, even more than the semiperiphery. Their greater comparative wealth relative to the semiperiphery and, to an even greater extent, the periphery, leads to economic expansion and concomitantly high levels of energy production and industrial activity, and hence to $\mathrm{CO} 2$ production.

It is in the semicore that much of the potential for air pollution and for the greenhouse effect are most clearly evidenced. As is true for the non-core, population growth in general leads to encroachment into rural or wilderness areas, which encourages environmental degradation (such as high levels of $\mathrm{CO} 2$ and $\mathrm{CH} 4$ production) in the semicore. When coupled with the opportunity for deforestation, which stems from their high level of technological power (relative to the semiperiphery and periphery), there is a comparably higher deforestation potential for semicore countries. This is exacerbated by the fact that reforestation is relatively unknown in the semicore, as compared with the core. In the process, there is the loss of carbon sinks, and the accompanying vital capacity for $\mathrm{CO} 2-$ oxygen exchanges.

In sum, the economic institutions and demographic dynamics of nations vary by worldsystem position. These processes further interact in influencing both the national level of greenhouse gas emissions and the processes by which those emissions are likely to occur. Industrial $\mathrm{CO} 2$ is disproportionately produced by core and semicore countries, due to their patterns of consumption, which in turn are related to their economic institutions. Demographic dynamics and land use in the semicore, and to a lesser degree the semiperiphery, exacerbate methane production.

[Page 444]

Journal of World-Systems Research

We use this overarching framework to inform our ensuing analyses. A schematic diagram, detailing concepts and their linkages in our conceptual framework, is presented in Figures 1 and 2. 
Figure 1. Model of World-System and National Attribute Links to Emissions of $\mathrm{CO}_{2}$

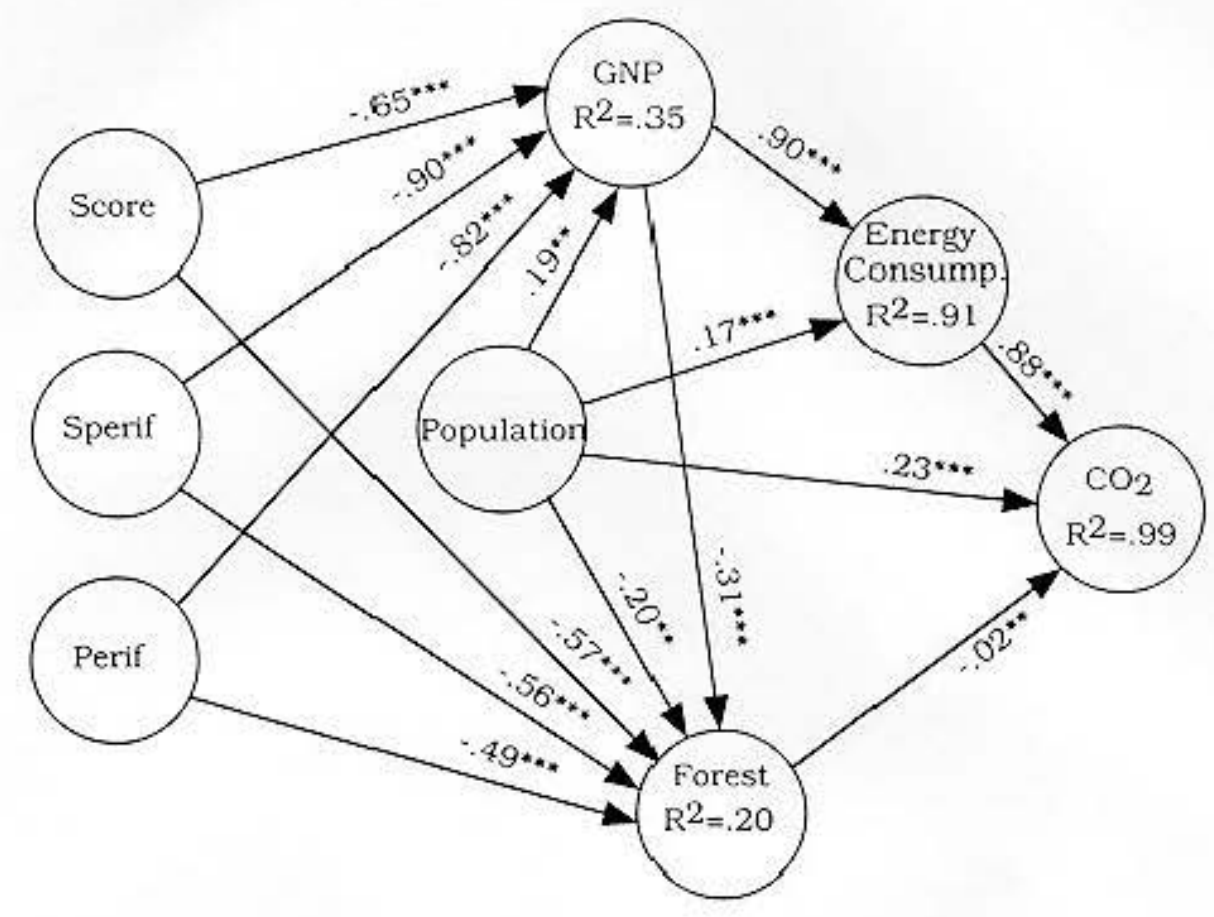

$*: t>1.5$

$* *: t>2.0$

$* * *: t>2.5$

$\mathrm{CO}_{2}=$ Carbon Dioxide Emissions (Ave 1988-91)

Forest $=$ Change in Forestation (1991-1960)

Energy Consump. = Energy Consumption (Ave 1975-85)

GNP = Gross National Product (Ave 1975-85)

Population $=$ Population (Ave 1975-85)

Score $=$ World System Position Semi-Core Dummy Variable $($ Ref $=$ Core $)$

Sperif = World System Position Semi-Periferal Dummy Variable (Ref.=Core)

Perif $=$ World System Position Periferal Dummy Variable (Ref.=Core) 
Figure 2. Model of World-System and National Attribute Links to Emissions of Methane

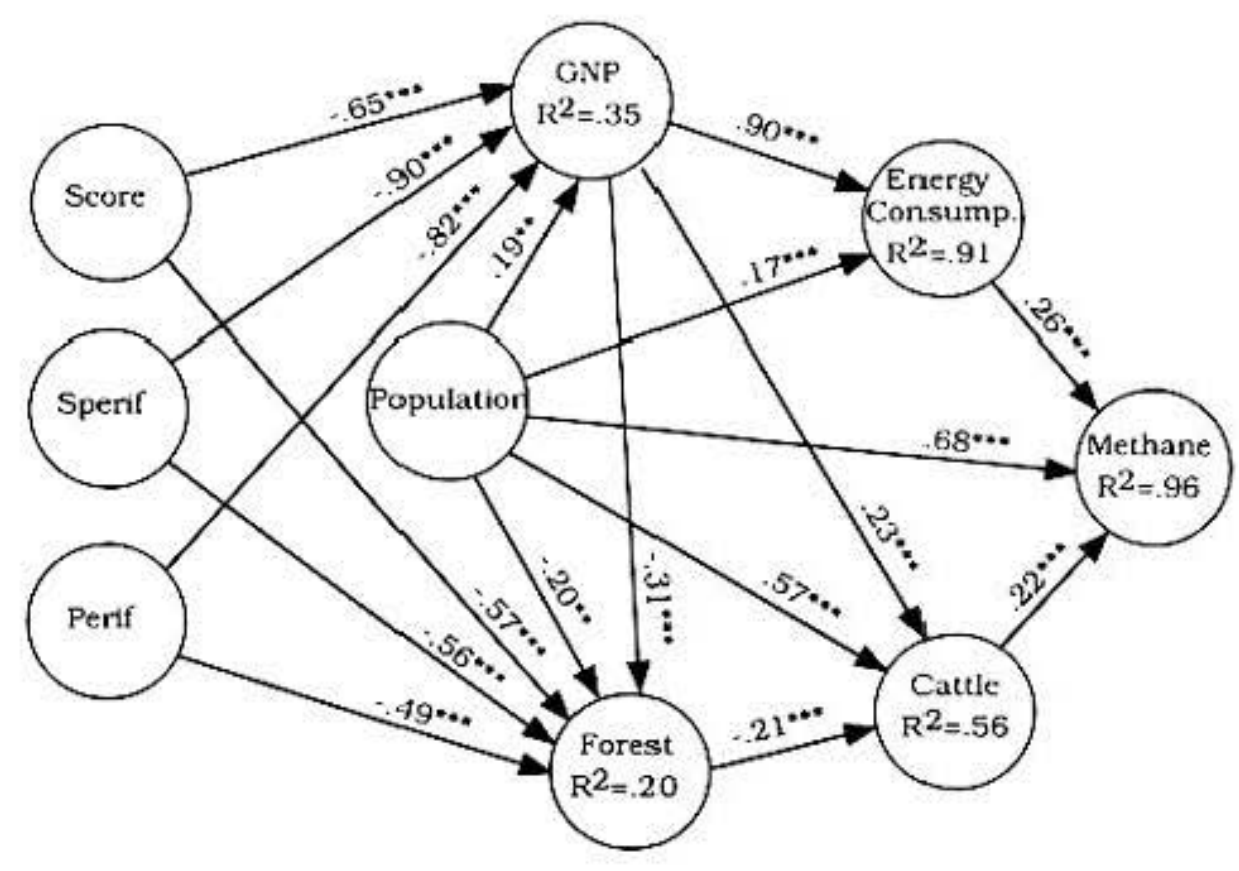

$* t>1.5$

$* \cdot t>2.0$

$* *: t>2.5$

Methane $=$ Methane Emissions (1991)

Cattle $=$ Number of Cattle (Ave 1983-87)

Energy Consump. = Energy Consumption (Ave 1975-85)

Forest $=$ Change in Forestation $(1991-1960)$

GNP $=$ Gross National Product (Ave 1975-85)

Population $=$ Population (Ave 1975-85)

Score $=$ World System Position Semi-Core Dummy Variable $($ Ref $=$ Core $)$

Sperif $=$ World System Position Semi-Periferal Dummy Variable (Ref. $=$ Core)

Perif $=$ World System Position Periferal Dummy Variable $($ Ref.$=$ Core $)$

\section{METFODXLOGY}

\section{Sample}

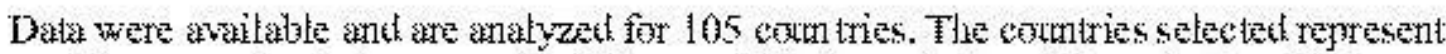

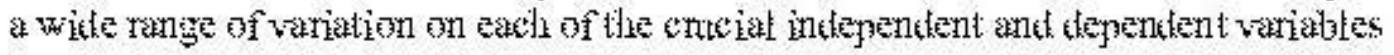


indicating the constructs discussed above. (See Appendix I). Our data are taken from the World Resources Institute (1994) data set.

\section{Analytical Technique}

Central tendency and variance statistics were generated, as were zero-order correlations among the variables in our model. They are summarized in Table 1.

$\begin{array}{lrc}\text { Table 1: Means, Standard Deviations, and Correlations } \\ \text { Variable } & \text { Mean } & \text { Std Deviation } \\ \text { CO2 } & 152357.784 & 550802.352 \\ \text { METHE } & 2009.510 & 5944.562 \\ \text { GNP } & 109497.510 & 422313.953 \\ \text { CATTLE } & 10228.164 & 25993.038 \\ \text { ENRC } & 1766771.196 & 7110718.082 \\ \text { FRST } & -2133.305 & 7751.555 \\ \text { POP } & 37083.785 & 119813.238 \\ \text { CORE } & .105 & .308 \\ \text { SCORE } & .162 & .370 \\ \text { SPERIF } & .457 & .501 \\ \text { PERIF } & .276 & .449\end{array}$

Correlations

\begin{tabular}{|c|c|c|c|c|c|c|c|c|}
\hline & $\mathrm{CO} 2$ & METHE & GNP & CATTLE & ENRC & FRST & POP & CORE \\
\hline $\mathrm{CO} 2$ & 1.000 & .743 & .873 & .517 & .972 & -.274 & .558 & .375 \\
\hline METHE & .743 & 1.000 & .456 & .799 & .609 & -.336 & .925 & .126 \\
\hline GNP & .873 & .456 & 1.000 & .386 & .937 & -.156 & .222 & .562 \\
\hline CATTLE & .517 & .799 & .386 & 1.000 & .460 & -.401 & .677 & .091 \\
\hline ENRC & .972 & .609 & .937 & .460 & 1.000 & -.215 & .369 & .435 \\
\hline ERST & -.274 & -.336 & -.156 & -.401 & -.215 & 1.000 & -.276 & .179 \\
\hline POP & .558 & .925 & .222 & .677 & .369 & -.276 & 1.000 & .052 \\
\hline CORE & .375 & .126 & .562 & .091 & .435 & .179 & .052 & 1.000 \\
\hline SCORE & .081 & .158 & -.042 & .094 & .035 & -.226 & .144 & -.150 \\
\hline SPERIF & -.139 & -.056 & -.175 & -.014 & -.157 & .006 & -.014 & -.314 \\
\hline PERIF & -.169 & -.154 & -.156 & -.124 & -.152 & .057 & -.138 & -.211 \\
\hline & SCORE & SPERIF & PERIF & & & & & \\
\hline $\mathrm{CO} 2$ & .081 & -.139 & -.169 & & & & & \\
\hline METHE & .158 & -.056 & -.154 & & & & & \\
\hline GNP & -.042 & -.175 & -.156 & & & & & \\
\hline CATTLE & .094 & -.014 & -.124 & & & & & \\
\hline ENRC & .035 & -.157 & -.152 & & & & & \\
\hline FRST & -.226 & .006 & .057 & & & & & \\
\hline POP & .144 & -.014 & -.138 & & & & & \\
\hline CORE & -.150 & -.314 & -.211 & & & & & \\
\hline SCORE & 1.000 & -.403 & -.272 & & & & & \\
\hline SPERIF & -.403 & 1.000 & -.567 & & & & & \\
\hline PERIF & -.272 & -.567 & 1.000 & & & & & \\
\hline
\end{tabular}


Product

Methe = Methane Emissions (1991); GNP = Gross National

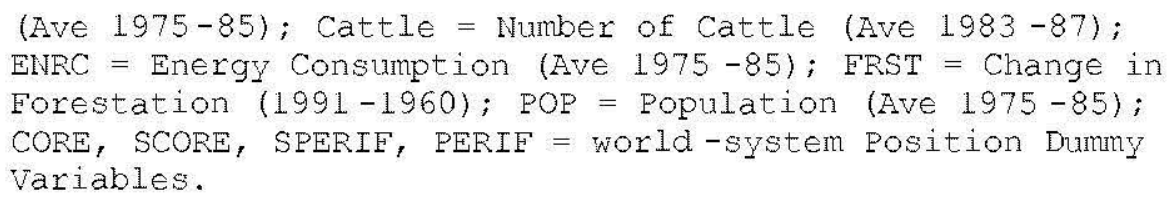

We use ordinary least-squares regression to test key facets of the theoretical framework we propose.

[Page 445]

Journal of World-Systems Research

\section{Outcome Variables}

We use two dependent variables. The data are for circa 1990 and reflect carbon dioxide (CO2) emissions from industrial sources and methane (CH4) emissions. In concert with our focus on the worldwide nature of the problem of the greenhouse effect, and the cumulative and shared effect of greenhouse gas emissions, both variables are reported in total output of emissions produced (as opposed to, for example, per capita output).

\section{Predictor Variables}

We employ four mediating variables that serve as indicators for the causal processes detailed above. They include: the national institutionalization of economic development (measured by gross national product, averaged over 1975-1985); energy consumption (averaged over 1975-1985); total cattle population, as an indicator of agricultural activity (averaged over 1983-1987); and the amount of forested area (in 1991, relative to 1960).

As an exogenous variable, we include average population over the period 1975-1985. The other exogenous variables in our regression estimations reflect nations' respective positions in the modern world-system measured circa the early $1970 \mathrm{~s}$. Their respective effects are assessed using "dummy variable" analysis, which permits examination of the relative effects of each structural position indicator compared with the other three.

[Page 446]

Joumal of World-Systems Research

\section{Operationalizing the World-System}

The literature is rife with conflicting operationalizations of the world-system, and the most problematic sector is the "elusive" semiperiphery (Terlouw 1993). As Arrighi and 
Drangel point out, Wallerstein's (1979) list of semiperipheral states collectively account for about two-thirds of the world's population.

We acknowledge the problems inherent in treating the semiperiphery as a monolithic bloc. Previous research based on a multiple-network theoretic model (Kick 1987; also see Kick et al. 1995), indicates a relatively more central (in multiple network theoretic terms) and less central part of the semiperiphery, which we label as the "semicore" and "semiperiphery," respectively.

Admittedly, our taxonomy is somewhat arbitrary — an alternative might be "stronger semiperiphery" and "weaker semiperiphery," respectively. Nemeth and Smith (1985), for example, derive four positions in the world-system-a core, a periphery, and a twotiered semiperiphery, which they label as "strong semiperiphery" and "weak semiperiphery." In testing the predictive validity of their scheme, Nemeth and Smith typically find "monotonic" relationships between their outcomes (e.g. average annual growth in GNP per capita, and child mortality), such that the core is in the most favorable position, the periphery in the least favorable, and the semiperipheries rest in between. A problem with the Nemeth and Smith (1985) scheme is the absence of communist-bloc countries, many of which are in either the semicore or the semi-periphery. That notwithstanding, Nemeth and Smith make a key distinction between a strong and weak semiperiphery in which, on balance, the strong semiperiphery has characteristics that in some ways resemble those of the core. The 'weak semiperiphery,' while significantly stronger than the periphery, is in a disadvantaged position relative to the 'strong semiperiphery' in terms of international trade networks.

[Page 447]

Journal of World-Systems Research

Kick (1987) acknowledges multiple networks of global power and dependence.

Dominance in one network area may be used to generate dominance in another; for example, political and military networks enforce core control and foster its global economic gain and cultural hegemony (for further discussion, see Mann 1986). Yet Nemeth and Smith (1985) criticize work such as Kick's (1987), which derives a worldsystem classification on a multitude of networks in addition to economic ones. For example, they criticize Snyder and Kick (1979) for deriving blocs seemingly based on geographic similarity. As Fain et al. (1995) demonstrate, however, geography itself is a strong predictor, along with economic, political and military considerations, of worldsystem position.

Nemeth and Smith (1985), and work stemming from it (e.g. Smith and White 1992), is biased in the way that much world-system work is - namely that it largely ignores factors other than those directly associated with economics. While this may be defensible in a study ignoring the communist-bloc countries, it would be problematic in one including them. 
We argue here and elsewhere (e.g. Kick et al. 1995), that the world-system cannot be reduced to economic processes only, even if the world economy can be. As an illustration, it is precisely in the transitional semicore that there is the least isomorphism between economics and politics. The semicore resembles the semiperiphery (e.g. economically), but has some characteristics in common with the core in other dimensions, such as politically. Yet the very inconsistency between the economic and political dimensions makes the semi-core vulnerable to crisis. In some cases, the crisis takes the form of revolution (as in '[W]hy did 1991 happen?'). The important point for present purposes is that this inconsistency can result in environmental crisis as well.

Given the aforementioned considerations, the country categorizations we use are shown in Appendix I and are reproduced from Kick (1987). In concert with our theorization, we consider four, rather than three world-system positions. Thus, we dummy code for four world-system positions, with the omitted category (for model identification purposes) being the core.

\section{RESULTS}

Before analyzing the relatively more complex regression results, we first consider the simple zero-order correlations among variables in our model, which are given in Table 1. We then turn attention to regression results, which are summarized in Figures 1 and 2. The coefficients reported generally conform with the modified world-system framework detailed above.

[Page 449]

Journal of World-Systems Research

In examining the zero-order correlations, it is apparent that the core is most closely associated with $\mathrm{CO} 2$ production, followed by the semicore, semiperiphery, and periphery, respectively. As expected, $\mathrm{CO} 2$ production is very highly associated with energy consumption, as it is with structural position in the world-system.

Methane production is not so monotonically associated with world-system position. The semicore has higher methane production than does even the core, which in turn has higher methane production than the semiperiphery. The periphery produces the least methane.

While in many respects the semicore resembles the semiperiphery, in other key respects it does not. Thus, while energy consumption and the related $\mathrm{CO} 2$ emissions are more or 
less linearly related to world-system position (thus obviating any need to distinguish between strong and weak semiperiphery), methane is not linearly related to world-system position (at least in terms of zero-order relationships). In this regard, the strong semiperiphery (semicore) much more closely resembles the core than it does the (weaker) semiperiphery, and in fact is more closely associated with methane production than is even the core itself.

The zero-order correlations in themselves tell an important story. Additionally, in examining the figures relating world-system position to carbon dioxide and methane production, a number of possible indirect effects are worthy of note.

[Page 450]

Journal of World-Systems Research

Effects of world-system position on methane emissions can be understood, in part, through consideration of the mediating effects of cattle production. We attribute this to methane production, at least in part, to the gradual movement of agribusiness (e.g., cattle ranching for beef, much of which eventually is exported to core countries) from the core to the semiperiphery-but more specifically the more strongly networked portions of the semiperiphery (which we herein characterize as the semicore).

World-system impacts on economic strength (in this case, GNP) are precisely in line with the expectation that the world hierarchy perpetuates the core's wealth advantages over the non-core. Further, there are expected costs to noncore status that become progressively more pronounced in the semicore (SCORE), semiperiphery (SPERIF), and periphery (PERIF), respectively $\underline{2}$.

Forestation is affected as well by world-system position. In perusing the zero-order correlations in Table 1, it is apparent that the greatest deforestation is in the semicore. The favorable (positive) sign associated with the impact of core position represents the core's natural forest endowments and reforestation programs, as discussed earlier. Semicore and, to a lesser extent, semiperipheral, nations are able to employ their technology for deforestation of their abundant forests without concerted replacement efforts, and to do so with a higher level of efficiency than the less developed economies of the periphery. To be sure, however, semicore deforestation reflects both domestic consumption and core involvement (e.g., through international timber trade) in local deforestation processes.

[Page 451]

Journal of World-Systems Research 
Although its effects are dampened in the fully controlled regression model (beta $=-.02$ ), the zero-order correlations show a moderate (negative) correlation $(-.27)$ between forest growth and $\mathrm{CO} 2$ production. For methane production as well, there is a moderate negative correlation $(-.34)$ with forest growth.

In the periphery and elsewhere, population is a global and generic force that heightens the world's deforestation potential. The roles of population, economic expansion, and to an extent deforestation, are additionally crucial for $\mathrm{CO} 2$ and $\mathrm{CH} 4$ emissions and their attendant greenhouse effects. As reflected in the population size and economic expansion (GNP) coefficients, human consumption and production directly contribute to carbon dioxide emissions. As anticipated, economic expansion (GNP) indirectly contributes to increasing levels of industrial $\mathrm{CO} 2$. Put another way, ever expanding economies consume and produce energy that directly heightens $\mathrm{CO} 2$ and hastens the greenhouse effect.

Similarly, population pressures exacerbate methane production directly and indirectly. Population pressures directly elevate national methane levels, while population heightens cattle stocks as well, which in turn generate even greater methane emissions.

[Page 452]

Journal of World-Systems Research

A reliance upon livestock for farming, when coupled with the swelling of populations, escalates national and global methane emissions. These dynamics are characteristic primarily of the semicore. In contrast, the relatively higher standard of living that is characteristic of the core culminates in mounting carbon dioxide emissions. We further note the untested possibility that as post-industrial societies retain their high consumption levels but import energy and goods (e.g. meat, wood) produced in other world sectors, the net effect will likely reduce production-related emissions in the core, while increasing them for the producers (e.g., the semicore and semiperiphery).

\section{CONCLUSIONS}

In examining the social concomitants of greenhouse gas emissions, we find that $\mathrm{CO} 2$ production is most closely associated with the core position in the world-system, and that methane production is most closely associated with the semicore position. We believe both of these associations can be best understood in a world-system framework.

While certainly there are strong overlaps between economic networks and those in other dimensions (such as political and military), they are by no means isomorphic. Terlouw (1993), for example, examines six different types of networks, and generates two primary dimensions of relative strength in the world-system: economic and political. He acknowledges, in addition to the ideal typical semiperiphery (which has characteristics of both the core and the periphery in roughly equal measure), a "political semiperiphery" and an "economic semiperiphery" (p. 92). The important point for our work is that these 
different types of semiperipheries are likely to differ in a number of outcomes, such as environmental impact.

[Page 453]

Journal of World-Systems Research

Arrighi and Drangel (1986) theorize that economic strength is not necessarily parlayed into political strength, because "'wealth' can be accumulated more easily than 'power"" (pp. 23-24). The converse, however, can sometimes be true. Terlouw argues that a primary characteristic of a semiperipheral nation that is attempting to move up in the world system is "intense state intervention in the economy [which] is needed to stimulate national production" (p. 96). Thus, the combination in question would appear to be a strong state, which can simultaneously use its power to apply modern technology on a scale that potentially could compete with the core, while not having the kind of environmental regulations which, if found at all, are found primarily in the core. The combination thus has the potential of ecological catastrophe.

Those stronger semiperipheral countries which we characterize as the semicore, to the extent they are potentially mobile, are likely to use what economic strength they have in order to industrialize, in combination with political strength to push their advantages. This can have devastating consequences for the environment because these countries are under great competitive pressure and are unlikely to devote many resources to environmental protection.

[Page 454]

Journal of World-Systems Research

As has been pointed out elsewhere, a significant portion of semiperipheral nations are potentially upwardly or downwardly mobile in the world-system. While much of the semiperiphery forms a potentially stable intermediary in the world-system between the core and the periphery (Wallerstein 1974), the semicore poses at least a potential challenge to the hegemony of the core. In hopes of moving up in the hierarchy, it makes a number of sacrifices, such as using any available natural resources (both domestic and those it is able to use its political and military linkages to import). Having failed to achieve stability as a core power, it is less likely than the core to enact measures more typical of societies with a surplus, such as enacting the kinds of environmental protections found in the core.

The relationship between world-system position and at least some environmental outcomes is not monotonic in the way that other (e.g. economic) outcomes are. Other preliminary work indicates that the most severe degradation is occurring in the intermediate positions (Burns et al. 1994; Roberts and Grimes 1992). From what we are 
able to tell here, the greatest deforestation appears to be occurring in the semicore, as does the greatest methane production. Subsuming the semicore into the semiperiphery for analysis purposes attributes the problem to the semiperiphery, albeit in a somewhat dampened form. In fact, the semicore and the semiperiphery appear to have profoundly different profiles in terms of at least some outcomes. Other outcomes (e.g. CO2) do appear to follow world-system position virtually monotonically, largely because of standard of living sorts of factors, most notably energy consumption.

[Page 455]

Journal of World-Systems Research

The important point here, is that while certain aspects of environmental impact appear to be linearly related to level in the world-system, others do not. Energy consumption, for example, is greatest in the core and least in the periphery, with intermediate positions in the world-system associated with intermediate levels of energy consumption. Other relationships are not linear. Further, it may well be that by examining other environmental phenomena (e.g. toxic waste imports), the periphery could show up more prominently.

This is not to imply a lack of efficacy of a world-system analytic framework. On the contrary, world-system dynamics (e.g. concentration of wealth and power in the core), are likely to manifest themselves in a number of ways, which may include environmental outcomes that are most severe somewhere other than the core.

These are some of the worldwide causes of global warming, but relatively little social science theorizing and research addresses such environmental issues. We have constructed a preliminary theoretical framework and analytical examination to move toward addressing this need.

[Page 456]

Journal of World-Systems Research

The findings from this study point to interdependencies among global social structures and environmental outcomes. Aside from the specific causal mechanisms detailed above, we think it critical to emphasize that, like so many domestic processes, greenhouse gas emissions are products of indigenous forces which are themselves conditioned by the operation of a global system of power and dependency.

Policy implications spring directly from this understanding. The most generic implication is that efforts to limit global greenhouse gas production will not be successful if they are conducted on an ad hoc, nation-by-nation basis. The formation and activities of global agencies will prove relatively ineffectual if the socio-environmental interdependencies of 
the world operate to counter such interventions. Consider that worldwide efforts to curtail the $\mathrm{CO} 2$ and $\mathrm{CH} 4$ levels of non-core countries will prove to be impotent to the degree they manifestly challenge other key national agendas in the Third World, such as economic development. These national agendas and the institutional processes from which they stem are influenced in no small way by global forces.

In concluding, we emphasize the preliminary nature of this work. Many rigorous studies have been done on the greenhouse effect from the standpoints of the respective physical and life sciences. While these serve an important function in understanding the proximal physical mechanisms of the greenhouse effect, we point out that social arrangements are at least as important, and have a profound effect on such proximate physical mechanisms. Those social arrangements have international implications.

[Page 457]

Journal of World-Systems Research

We hope that our study will encourage further work in increasingly precise specification of the social processes involved in environmental degradation, as manifested in greenhouse gas emissions, pollution and resource depletion. Such research has profound implications for policy- makers, and not only on the local and national levels. While policy is promulgated most forcefully at the nation-state level, many environmental problems (and very notably the greenhouse effect) do not conform to nation-state boundaries. Thus, we urge continuing intergovernmental dialogue, as well as much more social scientific research, on environmental problems.

[Page 458]

Journal of World-Systems Research

\section{APPENDIX I}

\section{LISTING BY STRUCTURAL POSITION OF 105 COUNTRIES}

(taken from Kick, 1987)

CORE: Canada, Denmark, France, Italy, Japan, Netherlands, Spain, Sweden, Switzerland, United Kingdom, United States

SEMICORE: Australia, Austria, Brazil, Bulgaria, China, Czechoslovakia (former), Finland, Greece, Hungary, Ireland, Israel, New Zealand, Norway, Poland, Portugal, Romania, Yugoslavia (former) 
SEMIPERIPHERY: Algeria, Argentina, Bolivia, Chile, Colombia, Costa Rica, Dominican Rep., Ecuador, Egypt, El Salvador, Ghana, Guatemala, Guyana, Haiti, Honduras, India, Indonesia, Iran, Iraq, Jamaica, Jordan, Kenya, Korea, Rep., Kuwait, Liberia, Libya, Malaysia, Mexico, Morocco, Nicaragua, Nigeria, Pakistan, Panama, Paraguay, Peru, Philippines, Saudi Arabia, Singapore, South Africa, Sri Lanka, Syrian Arab Rep., Thailand, Trinidad and Tobago, Tunisia, Turkey, Uruguay, Venezuela, Zaire

PERIPHERY: Angola, Bangladesh, Benin, Burundi, Cameroon, Central African Rep., Chad, Congo, Cote d'Ivoire, Ethiopia, Gabon, Gambia, Laos People's Dem Rep., Madagascar, Malawi, Mali, Mauritania, Nepal, Niger, Rwanda, Senegal, Sierra Leone, Somalia, Sudan, Tanzania, Togo, Uganda, Zambia, Zimbabwe

[Page 459]

Journal of World-Systems Research

\section{REFERENCES}

Anderson, Anthony B. 1990. Smokestacks in the Rainforest: Industrial Development and Deforestation in the Amazon Basin. World Development, 18(9):1191-1205.

Arrighi, Giovanni, and Jessica Drangel. 1986. The Stratification of the World-Economy: An Exploration of the Semiperipheral Zone. Review, 10:9-74.

Bergesen, Albert. 1983. Modeling Long Waves of Crisis in the World-System. In Bergesen, Albert (ed.), Crises in the World System, pp. 73-92. Beverly Hills, CA: Sage.

Bergesen, Albert. 1992. Communism's Collapse: A World-System Explanation. Journal of Political and Military Sociology, 70:133-151.

Bunker, Stephen G. 1984. "Modes of Extraction, Unequal Exchange, and the Progressive Underdevelopment of an Extreme Periphery: The Brazilian Amazon, 1600-1980." American Journal of Sociology, 89:1017-1064.

Burns, Thomas J., Byron L. Davis, and Edward L. Kick. 1995. Effects of Foreign Trade and Domestic Development on Deforestation: A World-System Perspective. Paper presented at annual meeting of the American Sociological Association, Washington, D.C.

Burns, Thomas J., Edward L. Kick, David A. Murray, and Dixie A. Murray. 1994. Demography, Development and Deforestation in a World-System Perspective. International Journal of Comparative Sociology, 35(3-4):221-239.

[Page 460]

Journal of World-Systems Research 
Buttel, Frederick. 1987. New Directions in Environmental Sociology. Annual Review of Sociology, 13:465-488.

Carbon Dioxide Assessment Committee (CDAC). 1983. Changing Climate. Washington, D.C.: Natural Resources Council, National Academy Press.

Chase-Dunn, Christopher. 1990. Resistance to Imperialism: Semiperipheral Actors. Review, 13(1):1-31.

Cook, E. 1971. The Flow of Energy in an Industrial Society. Scientific American, $224: 134-147$.

Davis, Byron, Edward L. Kick, and Thomas J. Burns. 1995. Military Participation and Educational Expansion as Alternative Paths to Third World Development. Paper presented at annual meeting of the Pacific Sociological Association, San Francisco, California.

DeWalt, Billie R. 1983. The Cattle Are Eating the Forest. Bulletin of the Atomic Scientists, 39(1):18-23.

Dunlap, Riley E., and William R. Catton. 1978. Environmental Sociology: A New Paradigm. American Sociologist, 13:41-49.

Dunlap, Riley E., and William R. Catton. 1979. Environmental Sociology. Annual Review of Sociology, 5:243-273.

[Page 461]

Journal of World-Systems Research

Elnagheeb, A.H., and D. W. Bromley. 1994. Extensification of Agriculture and Deforestation: Empirical Evidence from Sudan. Agricultural Economics, 10(2):193-200.

Fain, Heidi D., Edward L. Kick, Byron Davis, and Thomas J. Burns. 1995. WorldSystem Position, Social and Environmental Variability, and Population Stability. Paper presented at annual meeting of Society of Human Ecology, Tahoe City, California.

Grimes, Peter, and J. Timmons Roberts. 1993. Social Roots of Environmental Damage: A World-Systems Analysis of Global Warming. Paper Presented at annual Meeting of the American Sociological Association, Miami, Florida. 
Grimes, Peter, and J. Timmons Roberts, 1995. Oscillations in Atmospheric Carbon Dioxide and Long Cycles of production in the World Economy, 1790-1990. Paper presented at annual meeting of the American Sociological Association, Washington, D.C.

Kaoneka, Ars, and B. Solberg. 1994. Forestry Related Land Use in the Western

Usambara Mountains, Tanzania. Agriculture, Ecosystems and Environment, 49:207-215.

Kick, Edward L. 1987. World-System Structure, National Development, and the Prospects for a Socialist World Order. In Terry Boswell, and Albert Bergesen (eds.), America's Changing Role in the world-system, pp. 127-155. New York: Praeger.

Kick, Edward L., Byron Davis, Thomas J. Burns, and Oleg Gubin. 1995. International Multiple Networks in World-System Approaches. In M.G. Everett and K. Rennolls (eds.) International Conference on Social Networks, Vol. 3, pp. 237-248. London: Greenwich University Press.

[Page 462]

Journal of World-Systems Research

Kick, Edward L., Thomas J. Burns, Byron L. Davis, David A. Murray, and Dixie A. Murray. 1996. Impacts of Foreign Wood Trade and Domestic Population Dynamics on Deforestation: A World-System Perspective. Journal of Developing Societies, 12(1):6887.

Kim, Kyungmo, and George A. Barnett. 1996. The Determinants of International News Flow: A Network Analysis. Communication Research, 23:323-352.

Kone, T. 1993. Structural Adjustment and Agricultural Policy in Cote d'Tvoire: Environmental Impact. Labor, Capital and Society, 26:86-101.

Laska, Shirley. 1993. Environmental Sociology and the State of the Discipline. Social Forces, $72: 1-17$.

London, Bruce. 1987. Structural Determinants of Third World Urban Change: An Ecological and Political Economic Analysis. American Sociological Review, 52:28-43.

Mann, Michael. 1986. The Sources of Social Power, Vol. I. Cambridge, U.K.: Cambridge University Press.

Miller, Kenton R., Walter V. Reid, and Charles V. Barber. 1991. Deforestation and Species Loss: Responding to the Crisis. Pp. 78-111 in Mathews, Jessica Tuchman (ed.). Preserving the Global Environment: The Challenge of Shared Leadership. New York: W. W. Norton. 
[Page 463]

Joumal of World-Systems Research

Nemeth, Roger, and David A. Smith. 1985. International Trade and World-System

Structure: A Multiple Network Analysis. Review, 8:517-560.

Niang, Cheikh I. 1990. From Ecological Crises in the West to the Energy Problem in Africa.

International Social Science Journal, 42:225-239.

Olsen, Marvin. 1990. The Energy Consumption Turnaround and Economic Well-Being in Industrial Societies in the 1980s. Paper presented at the World Congress of Sociology of the International Sociological Association, Madrid, Spain.

Rosa, Eugene A, G.E. Machlis, and K.M. Keating. 1988. Energy and Society. Annual Review of Sociology, 14:149-172.

Schneider, S. H. 1989. The Greenhouse Effect: Science and Policy. Science, 243:771781.

So, Alvin Y. 1990. Social Change and Development: Modernization, Dependency, and World System Theories. Newbury Park, Calif.: Sage.

Smith, David A. and Douglas R. White. 1992. Structure and Dynamics of the Global Economy: Network Analysis of International Trade 1965-1980. Social Forces, $70(4): 857-893$.

Snyder, David, and Edward L. Kick. 1979. Structural Position in the world-system and Economic Growth, 1955-1970: A Multiple Network Analysis of Transnational Interactions. American Journal of Sociology, 84:1096-1126.

[Page 464]

Journal of World-Systems Research

Stern, P.C., O.R. Young, and D. Druckman (eds.). 1992. Global Environmental Change: Understanding the Human Dimensions. Washington, D.C.: National Academy of Sciences, National Academy Press.

Terlouw, C.P. 1993. The Elusive Semiperiphery: A Critical Examination of the Concept of Semiperiphery. International Journal of Comparative Sociology, 34:87-102. 
Thiele, R., and M. Wiebelt. 1993. National and International Policies for Tropical Rain Forest Conservation - A Quantitative Analysis for Cameroon. Environmental and Resource Economics, 3(6):501-531.

Wallerstein, Immanuel. 1974. The Modern World-System: Capitalist Agriculture and the Origins of the European World-Economy in the Sixteenth Century. New York: Academic Press

Wallerstein, Immanuel. 1979. The Capitalist World Economy. New York: Cambridge University Press.

World Resources Institute, in collaboration with United Nations Environment Programme and United Nations Development Programme. 1994. World Resources 1994-95 [book and MRDF]. New York: Oxford University Press.

[Page 465]

Journal of World-Systems Research

\section{Endnotes:}

1. When political and economic strength do not match, there is a heightened potential for crisis. Bergesen (1992) uses a world-system framework, and theorizes that states are least stable in the semiperiphery (p. 143). He ties this to worldwide Kondratieff cycles, in which it is commonly the case that while economies are expanding, political structures typically are contracting, and vice-versa (also see Bergesen 1983). He attributes the collapse of many of the communist countries to this lack of stability, which was exacerbated in the 1980s by a Kondratieff B-phase, and the associated economic contraction and political overextension.

2 . We readily acknowledge that a fully specified model of this type undoubtedly would also incorporate a range of other demonstrated predictors of national wealth (e.g., investments, prior wealth, savings). Unfortunately the inclusion of the range of wealth predictors causes estimation problems, including severe multicollinearity. An array of quantitative evidence from a variety of empirical studies (e.g. Davis et al. 1995) shows that the position effects we report are sustained even when the influences of such causal forces are explicitly estimated. Indeed, the dummy-variables we use in some ways stand as proxies for these forces.

[Page 466]

Journal of World-Systems Research 